\title{
Trazodone increases arousal threshold in obstructive sleep apnoea
}

\author{
R.C. Heinzer*\#, D.P. White*, A.S. Jordan*, Y.L. Lo*, ", L. Dover*, \\ K. Stevenson* and A. Malhotra*
}

ABSTRACT: A low arousal threshold is believed to predispose to breathing instability during sleep. The present authors hypothesised that trazodone, a nonmyorelaxant sleep-promoting agent, would increase the effort-related arousal threshold in obstructive sleep apnoea (OSA) patients.

In total, nine OSA patients, mean \pm SD age $49 \pm 9 \mathrm{yrs}$, apnoea/hypopnoea index $52 \pm 32$ events $\cdot h^{-1}$, were studied on 2 nights, one with trazodone at $100 \mathrm{mg}$ and one with a placebo, in a double blind randomised fashion. While receiving continuous positive airway pressure (CPAP), repeated arousals were induced: 1) by increasing inspired $\mathrm{CO}_{2}$ and 2) by stepwise decreases in CPAP level. Respiratory effort was measured with an oesophageal balloon. End-tidal $\mathrm{CO}_{2}$ tension $\left(\mathrm{PET}, \mathrm{CO}_{2}\right)$ was monitored with a nasal catheter.

During trazodone nights, compared with placebo nights, the arousals occurred at a higher $\mathrm{PET}_{,} \mathrm{CO}_{2}$ level (mean $\pm \mathrm{SD} 7.30 \pm 0.57$ versus $6.62 \pm 0.64 \mathrm{kPa}(54.9 \pm 4.3$ versus $49.8 \pm 4.8 \mathrm{mmHg})$, respectively). When arousals were triggered by increasing inspired $\mathrm{CO}_{2}$ level, the maximal oesophageal pressure swing was greater $\left(19.4 \pm 4.0\right.$ versus $\left.13.1 \pm 4.9 \mathrm{cmH}_{2} \mathrm{O}\right)$ and the oesophageal pressure nadir before the arousals was lower $\left(-5.1 \pm 4.7\right.$ versus $\left.-0.38 \pm 4.2 \mathrm{cmH}_{2} \mathrm{O}\right)$ with trazodone. When arousals were induced by stepwise CPAP drops, the maximal oesophageal pressure swings before the arousals did not differ.

Trazodone at $\mathbf{1 0 0} \mathbf{~ m g}$ increased the effort-related arousal threshold in response to hypercapnia in obstructive sleep apnoea patients and allowed them to tolerate higher $\mathrm{CO}_{2}$ levels.

KEYWORDS: Arousal threshold, carbon dioxide, oesophageal pressure, sleep-disordered breathing, trazodone

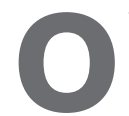
bstructive sleep apnoea (OSA) syndrome is a common disorder occurring in at least $4 \%$ of middle-aged males and $2 \%$ of females [1]. It is characterised by repetitive pharyngeal collapse during sleep, leading to sleep disruption, arousals and nocturnal arterial oxygen desaturation.

Apnoeas and hypopnoeas typically end with an arousal. Arousal from sleep is, therefore, believed to be an important mechanism for re-establishing airway patency in OSA. However, a recent study by YOUNES [2] demonstrated that the airway opening can precede arousal and that there may be no arousal at the end of a respiratory event in some cases. This finding suggests that an arousal is not always needed to restore flow after an apnoea or a hypopnoea. YounEs [2] also demonstrated that the occurrence of an arousal at upper airway opening (the end of the apnoea) is associated with a greater ventilatory overshoot and a greater subsequent undershoot, which may promote further breathing instability. This observation suggests that arousals may contribute to sleep apnoea severity.

Based on this concept, some authors have tried to treat sleep apnoea patients by increasing the arousal threshold with sedatives, such as benzodiazepines, without much success [3]. This failure may be due to a myorelaxant effect of benzodiazepine on upper airway dilator muscles. Trazodone is an antidepressant medication approved by the US Food and Drug Administration in 1982. It appears to work by increasing brain levels of serotonin (5-hydroxytryptamine) but is chemically unrelated to the selective serotonin reuptake inhibitors, the tricyclic antidepressants (TCAs) or the monoamine oxidase inhibitors. Trazodone is also one of the most widely used sleep-promoting agents in the USA. The present authors hypothesised that trazodone would increase the arousal threshold based on its hypnotic properties. However,
AFFILIATIONS

*Sleep Medicine Division, Brigham and Women's Hospital, Harvard Medical School, Boston, MA, USA, ${ }^{\#}$ Service de Pneumologie et Centre d'Investigation et de Recherche sur le Sommeil (CIRS), Centre Hospitalier Universitaire Vaudois (CHUV), Lausanne, Switzerland, and 'Dept of Thoracic Medicine, Chang Gang Memorial Hospital, Taipei, Taiwan.

\section{CORRESPONDENCE}

R.C. Heinzer

Service de Pneumologie

Centre d'investigation et de

Recherche sur le Sommeil (CIRS)

Centre Hospitalier Universitaire

Vaudois

CH-1011 Lausanne

Switzerland

Fax: 41213146752

E-mail: rheinzer@post.harvard.edu

Received:

June 052007

Accepted after revision:

January 222008

SUPPORT STATEMENT

This work was supported by the National Institutes of Health $(\mathrm{NIH})$, grants HL48531 and HL60292, NIH/ National Heart, Lung, and Blood Institute grant T32 HL007901, and $\mathrm{NIH/RR01032.} \mathrm{Support} \mathrm{was} \mathrm{also}$ received from the Fond National Suisse de la Recherche Scientifique (Bern, Switzerland), the Fondation SICPA (Lausanne, Switzerland) and the Société Académique Vaudoise (Lausanne).

\section{STATEMENT OF INTEREST}

Statements of interest for D.P. White and $A$. Malhotra can be found at www.erj.ersjournals.com/misc/ statements.shtml

European Respiratory Journal Print ISSN 0903-1936

Online ISSN 1399-3003 
unlike benzodiazepines, it should not decrease upper airway muscle activity, as serotonin, and specifically trazodone, has been shown to be a stimulant of upper airway muscle activity in an English bulldog model of sleep apnoea [4].

In normal subjects, arousal from nonrapid eye movement (NREM) sleep, secondary to hypoxaemia, without airway occlusion, whether isocapnic [5] or hypocapnic [6], is surprisingly inconsistent. Hypercapnia is generally a more potent arousal stimulus than hypoxaemia [7]. Studies of hyperoxic hypercapnia have found that arousal tends to occur when the end-tidal $\mathrm{CO}_{2}$ tension $\left(P \mathrm{ET}, \mathrm{CO}_{2}\right)$ reaches $1.3-2.0 \mathrm{kPa}(10-$ $15 \mathrm{mmHg}$ ) above the baseline waking level [8]. In sleep apnoea patients, the mechanisms whereby apnoeas lead to arousal are not completely clear. Apnoeas are characterised by worsening hypoxaemia and hypercapnia in association with a progressive increase in respiratory effort. Although hypercapnia and
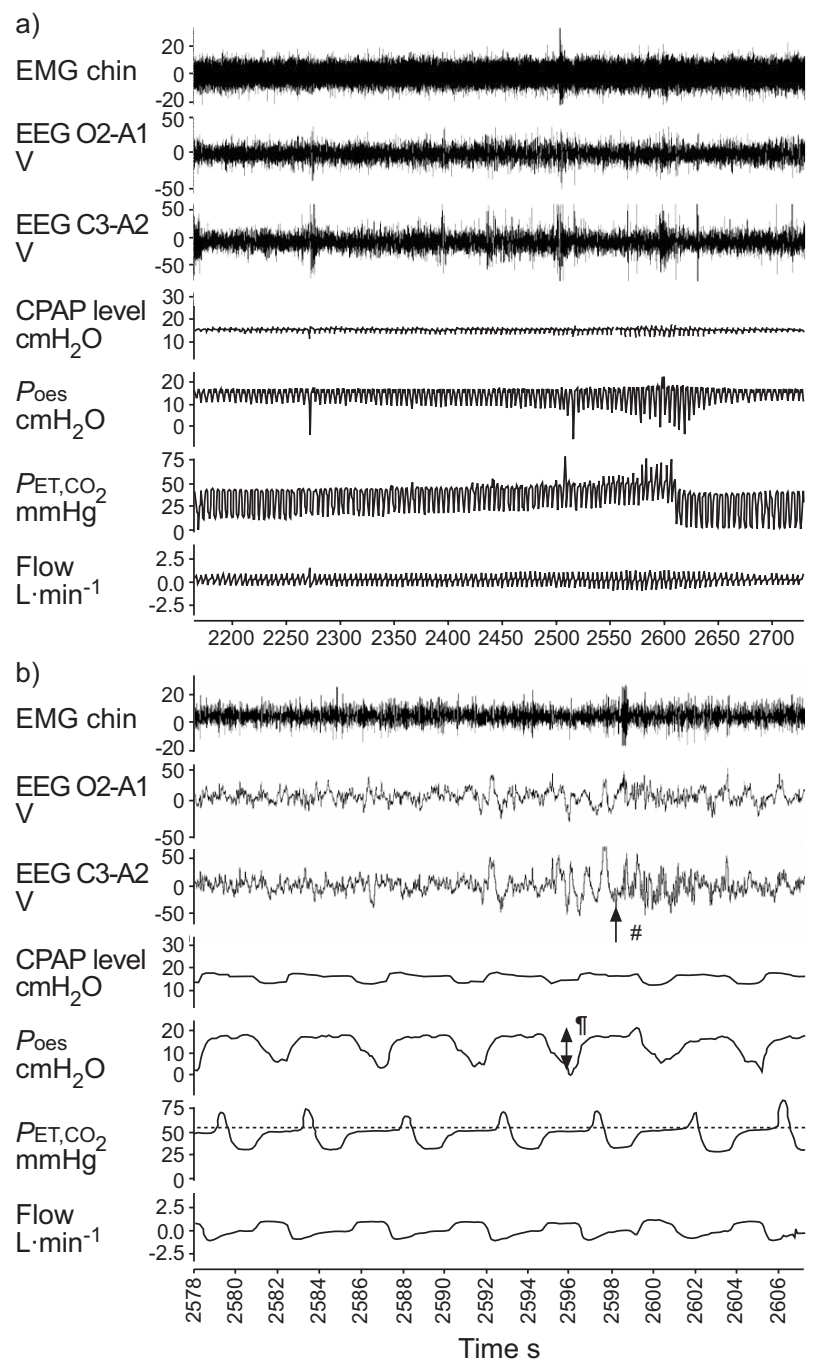

FIGURE 1. Example of an arousal induced by an increase in $\mathrm{CO}_{2}$. a) General view and $b$ ) increased magnification of $30 \mathrm{~s}$ during an arousal. EMG: electromyogram; EEG: electroencephalogram (tracings O2-A1 and C3-A2); CPAP continuous positive airway pressure; Poes: oesophageal pressure; $P \mathrm{ET}_{1}, \mathrm{CO}_{2}$ : endtidal $\mathrm{CO}_{2}$ tension. $\cdots \cdot \cdot \mathrm{PET}, \mathrm{CO}_{2}$ level. *: arousal; $\because$ respiratory effort. $1 \mathrm{mmHg}=0.133 \mathrm{kPa}$. hypoxaemia occur during each apnoea, healthy subjects usually arouse at a specific level of negative intrathoracic pressure, suggesting that respiratory effort is the main stimulus to arousal [9]. However, because hypercapnia without respiratory effort has been reported to induce arousals [8], an independent role of hypercapnia cannot be ruled out. The present authors, therefore, sought to determine whether trazodone could increase the stimulus required to induce arousal from both increased inspired $\mathrm{CO}_{2}$ and progressive upper airway collapse (stepwise continuous positive airway pressure (CPAP) drops). Some of the results of the present study have been reported previously [10].

\section{MATERIAL AND METHODS}

\section{Study subjects}

In total, 10 subjects with moderate-to-severe OSA determined by overnight polysomnography, who were treated with CPAP, were enrolled in the study. Subjects with any medical problems affecting the upper airway (other than OSA), or taking any drug having an interaction with trazodone were excluded from the study. Considering the results of GLEESON et al. [9], who reported that their subjects aroused at a mean $\pm S D$ oesophageal pressure of $-14.7 \pm 2.4 \mathrm{cmH}_{2} \mathrm{O}$, it was calculated that at least seven subjects were needed, in order to have $80 \%$ power to detect a $4 \pm 3 \mathrm{cmH}_{2} \mathrm{O}$ difference in oesophageal pressure swings (respiratory effort) between trazodone and placebo, using a paired t-test with $\alpha=0.05$. For the $\mathrm{CO}_{2}$ level before arousal, at least six patients were needed, to have $80 \%$ power to detect a $0.40 \pm 0.27 \mathrm{kPa}(3 \pm 2 \mathrm{mmHg})$ difference between trazodone and placebo, using a paired t-test with $\alpha=0.05$.

\section{Study design}

Subjects were studied on 2 nights under two different conditions, placebo or trazodone $100 \mathrm{mg}$ (taken orally, 90 min before bedtime), in a randomised (blocks of four) double blind crossover fashion. All data were analysed before the code of the randomisation was revealed. The placebo pills were produced by the hospital pharmacy and were indistinguishable from the trazodone tablets.

\section{Methods}

For the night studies, subjects reported to the Clinical Research Center (Beth Israel Deaconess Medical Center, Boston, MA, USA) at 20:00 h, having been without food intake for at least $4 \mathrm{~h}$. Paste-on electrodes were applied to the scalp, chin, chest and face to record the electroencephalogram (EEG), electromyogram, electro-oculogram and electrocardiogram. Nostrils were decongested with oxymetazoline hydrochloride, and one nostril was anaesthetised with $4 \%$ lidocaine $(1-1.5 \mathrm{~mL})$. A $10-\mathrm{cm}$ deflated latex balloon linked with a pressure catheter was inserted through the decongested, anaesthetised nostril and the tip of the catheter was located at the distal third of the oesophagus. Once in place, the balloon was partially inflated with $0.5 \mathrm{~mL}$ of air and connected to a calibrated pressure transducer. A mask was placed over the subject's nose and held in place with straps. A catheter was placed in front of the free nostril to measure $\mathrm{PET}_{\mathrm{ETO}} \mathrm{CO}_{2}$ (Capnograph/Oximeter Monitor; BCI, Waukesha, WI, USA). A pulse oximeter was used to monitor blood oxygen saturation. 

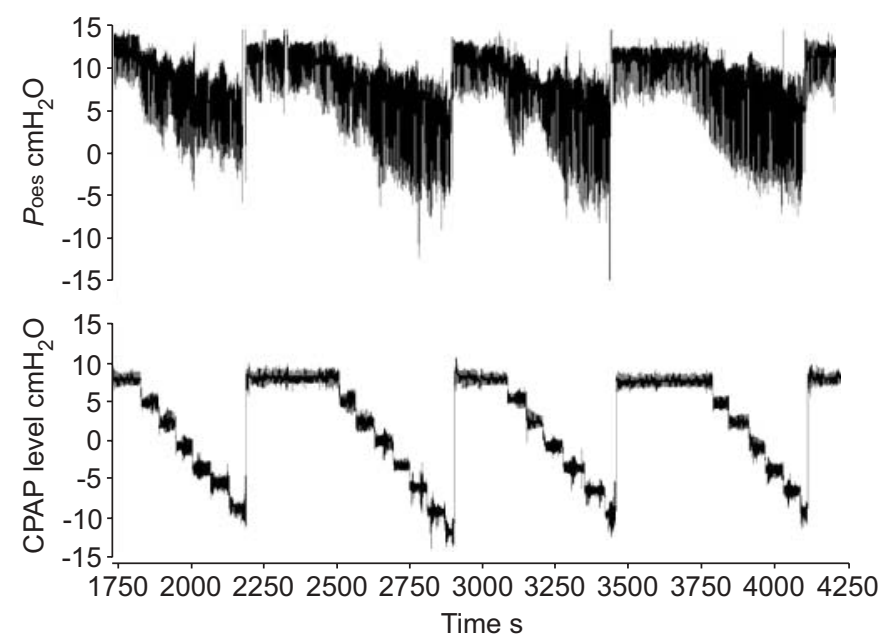

FIGURE 2. Stepwise continuous positive airway pressure (CPAP) level drops. Poes: oesophageal pressure.

The subjects were allowed to fall asleep with CPAP in place at their usual level. If needed, the CPAP level was titrated to eliminate any respiratory events or flow limitation. Once stable stage 2 NREM sleep was observed, $\mathrm{CO}_{2}$ was administered through the inspiratory line of the breathing apparatus. The $\mathrm{CO}_{2}$ level was gradually increased until the subject aroused from sleep (fig. 1). This procedure was repeated 10 times consecutively. The maximal $\mathrm{PET}, \mathrm{CO}_{2}$ the subjects could tolerate before they arose, as well as the oesophageal pressure just before the arousal, was recorded. An arousal was defined as an abrupt shift in EEG frequency which included the theta-alpha pattern and/or a frequency $>16 \mathrm{~Hz}$ (but not spindles) of $\geqslant 3 \mathrm{~s}$ duration.

During each night study, the CPAP level was also lowered in incremental steps of $3 \mathrm{cmH}_{2} \mathrm{O}$. If the subject did not have an arousal for $1 \mathrm{~min}$, the next $3-\mathrm{cmH}_{2} \mathrm{O}$ decremental step was performed. This was continued until the subject arose from sleep (fig. 2). The nadir oesophageal pressure and the maximal oesophageal pressure swings just prior to arousal were recorded. This procedure was repeated 10 times.

\section{Analysis}

Data were reported as mean $\pm \mathrm{SD}$. All data were analysed before the randomisation code was released. The same blinded investigator scored the arousals in all the recordings. To assess the maximal respiratory effort before the arousal, both the maximal oesophageal pressure swings (mean of the last three inspiratory efforts before the arousals) and the oesophageal

TABLE 1 Demographic data of the study subjects

$\begin{array}{lc}\text { Age yrs } & 49.9 \pm 9.5(37-64) \\ \text { AHI events } \cdot \mathbf{h}^{-1} & 52 \pm 32(24-99) \\ \text { BMI } \mathbf{~ g g} \cdot \mathbf{m}^{-2} & 31.2 \pm 4.5(24.7-36.8) \\ \text { Male/female } \mathbf{n} & 6 / 3\end{array}$

Data are presented as mean \pm SD (range), unless otherwise stated. $\mathrm{AHI}$ : apnoea/hypopnoea index; BMl: body mass index. pressure nadir before the arousals were determined. To compare the respiratory effort and $\mathrm{PET}_{1}, \mathrm{CO}_{2}$ prior to arousal between placebo and trazodone, a paired t-test was used, as each subject was his/her own control.

\section{RESULTS}

Of the 10 subjects enrolled, one could not complete the protocol because she felt weak and light-headed about $30 \mathrm{~min}$ after taking trazodone $100 \mathrm{mg}$ (randomisation code was broken for this patient). Therefore, the results of the other nine patients are reported. Demographic data are reported in table 1. During trazodone nights compared with placebo nights, the arousals occurred at a higher $P E T, \mathrm{CO}_{2}$ level (mean \pm SD $7.30 \pm 0.57$ versus $6.62 \pm 0.64 \mathrm{kPa}$ ( $54.9 \pm 4.3$ versus $49.8 \pm 4.8 \mathrm{mmHg})$, respectively; $\mathrm{p}=0.038)$. When arousals were triggered by increasing inspired $\mathrm{CO}_{2}$ level, the maximal oesophageal pressure swings (mean of the last three inspiratory efforts before the arousals) were greater (19.4 \pm 4.0 versus $13.1 \pm 4.9 \mathrm{cmH}_{2} \mathrm{O} ; \mathrm{p}=0.002$; fig. 3) and the oesophageal pressure nadir before the arousals was lower with trazodone $\left(-5.1 \pm 4.7\right.$ versus $-0.38 \pm 4.2 \mathrm{cmH}_{2} \mathrm{O} ; \mathrm{p}=0.02$; note that patients were receiving $(\mathrm{PAP})$. However, when arousals were induced by stepwise CPAP drops, the maximal oesophageal pressure swings before arousal did not differ between trazodone and placebo ( $16.9 \pm 6.3$ versus $15.5 \pm 6.9 \mathrm{cmH}_{2} \mathrm{O} ; \mathrm{p}=0.39$; fig. 3$)$. The difference in the oesophageal pressure nadir was also nonsignificant $\left(-6.0 \pm 8.2\right.$ versus $\left.-5.0 \pm 9.7 \mathrm{cmH}_{2} \mathrm{O} ; \mathrm{p}=0.53\right)$.

\section{DISCUSSION}

The main finding of the present study was that, in OSA patients, trazodone increased the respiratory effort-related arousal threshold in response to hypercapnia and allowed these individuals to tolerate a higher $\mathrm{CO}_{2}$ level without arousal. The current authors speculate that, in some OSA patients without a highly compromised upper airway, a low arousal threshold could contribute to the severity of their disease and a medication like trazodone might reduce apnoea severity. Conversely, in patients with a highly compromised pharyngeal airway, airflow resistance increases markedly during sleep and complete obstruction of the upper airway is common. In these patients, an increase in the arousal threshold would probably only extend the duration of the apnoea as an arousal will most likely be required to reopen the collapsed upper airway.

When an individual without a major anatomical airway problem falls asleep, the sleep-induced fall in upper airway dilator muscles may generate only a mild increment in resistance, which will result in a hypopnoea. Over time, the $\mathrm{O}_{2}$ tension falls, $\mathrm{CO}_{2}$ tension rises and ventilatory effort increases. Eventually one of two events must occur. On the one hand, the pharyngeal dilator muscles could be recruited adequately before the arousal occurs, thereby allowing sufficient ventilation for sleep to be maintained. On the other hand, an arousal could occur, accompanied by an abrupt increase in ventilation (overshoot), which would induce a subsequent apnoea or hypopnoea when the individual returns to sleep. In this second situation, if an arousal occurs each time there is a mild increase in upper airway resistance, the individual will wax and wane between sleep and wake with cycling respiratory events. Depending on the prevailing 

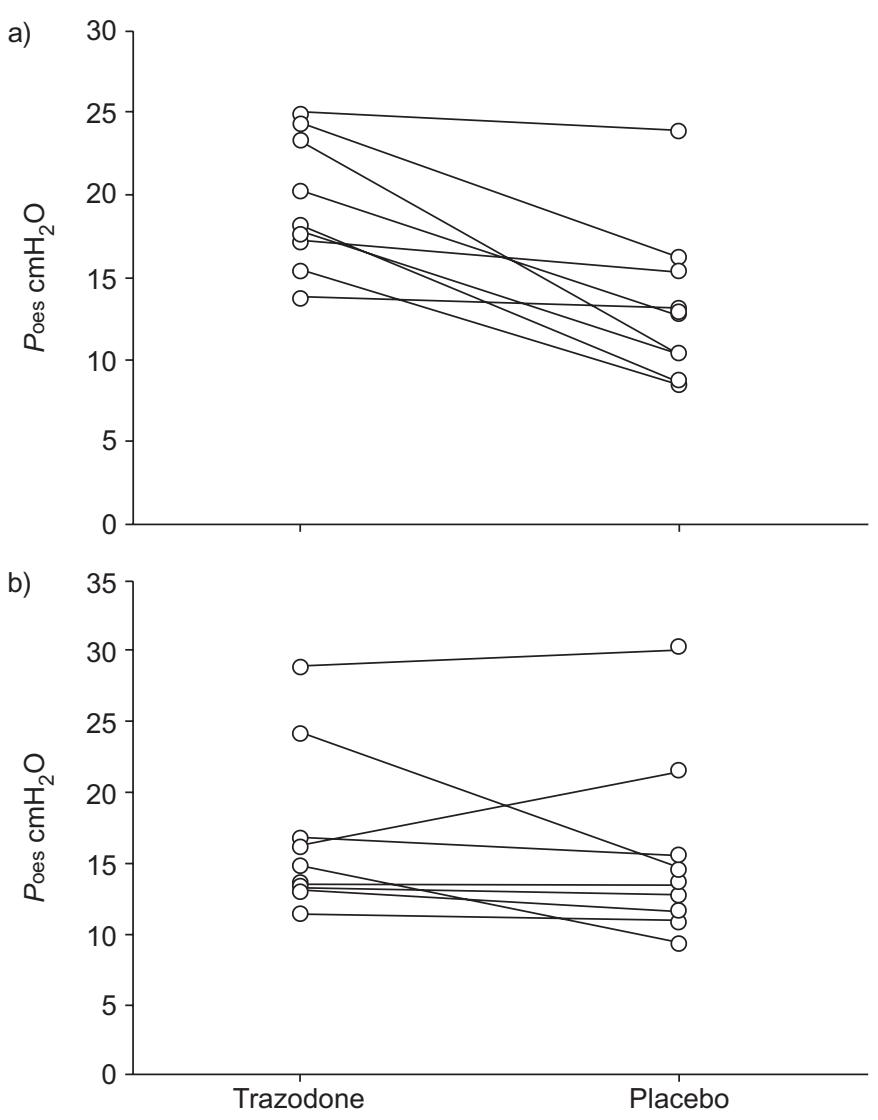

FIGURE 3. With trazodone, compared with placebo, subjects could tolerate higher respiratory effort before arousal when a) the arousal was induced by increased $\mathrm{CO}_{2}$ levels, but not when b) it was induced by continuous positive airway pressure drops. Poes: oesophageal pressure.

mechanics of the pharyngeal airway, either central or obstructive apnoea could result [11]. However, if one could increase the arousal threshold with a medication such as trazodone, the patient could potentially stay asleep long enough to recruit upper airway dilator muscles and reopen the upper airway without arousal [12]. In other words, an increase in arousal threshold in OSA patients with otherwise effective compensatory mechanisms during sleep could stabilise ventilation without arousal, at least in theory.

Other drugs have been used to treat OSA in the past. TCA medications, such as protriptyline, have been shown to increase hypoglossal nerve activity in cats [13]. However, this drug had only a modest effect on OSA in humans, which was probably mediated through suppression of rapid eye movement sleep [14, 15]. Benzodiazepines tend to decrease hypoglossal nerve activity in cats [13], as well as the tongue muscle in humans [16], but some positive effects have been reported in humans with central sleep apnoea [17]. BERRY et al. [3] have tried using a benzodiazepine (triazolam) to treat OSA patients. Although they did observe an increase in the arousal threshold, the apnoea/hypopnoea index did not decrease and the duration of the respiratory events mildly increased [3]. This negative result may be due to the lack of selection of OSA patients without a highly compromised upper airway. As mentioned previously, increasing the arousal threshold will certainly not help OSA patients with a highly collapsible upper airway, as they will probably need an arousal to restore pharyngeal patency. Moreover, benzodiazepines have a myorelaxant effect, which can decrease upper airway dilator muscle activity. Trazodone, at least in theory, has the opposite effect on the upper airway musculature because of its central serotoninergic effect, as suggested by VEASEY et al. [18]. Other drugs with serotoninergic activity, such as fluoxetine, mirtazapine and paroxetine, have been tested with some success in animals, although only limited success has been reported in humans, potentially due to minimal effects on the arousal threshold [15, 19-23].

There may be other reasons why suppression of arousal will not improve apnoea severity. Low upper airway dilator muscle "responsiveness" to $\mathrm{CO}_{2}$ during sleep may prevent an adequate response of pharyngeal muscles during an apnoea or hypopnoea, even if $\mathrm{CO}_{2}$ levels rise substantially. Marked instability in ventilatory control (high loop gain) or high ventilatory response to arousal [24] may also contribute to OSA severity, by inducing an excessive ventilatory response to a mild respiratory disturbance and promoting cyclic breathing [25]. Thus, suppression of arousal with drugs, such as trazodone, is not likely to help all OSA patients.

As there was such a clear effect of trazodone on the $\mathrm{CO}_{2-}$ induced arousal threshold, the present authors were surprised by the lack of a significant effect on the arousal threshold in response to a stepwise decrease in CPAP. When the CPAP level was dropped, some patients may have been aroused by the facial pressure difference or startle arousals more than by the increase in upper airway resistance. Another possibility is that trazodone is affecting arousal response to chemical stimuli (i.e. $\mathrm{CO}_{2}$ ) but not mechanical stimuli; however, if this were true it would challenge the notion that individuals awake at a specific oesophageal pressure, regardless of the stimulus (hypoxia, loading, hypercapnia) [9].

The main limitation of the present study is that the effect of trazodone was tested in artificial conditions (by increasing $\mathrm{CO}_{2}$ and decreasing CPAP level) and not during "natural" apnoea and hypopnoeas during sleep. Therefore, the effect of trazodone in clinical OSA is only speculative. These standardised conditions were, however, required for precise comparison of respiratory efforts between trazodone and placebo. The hypothesis of a beneficial effect of trazodone in a subset of OSA patients, with a mildly compromised upper airway and the ability to recruit muscles, will, therefore, have to be tested in future clinical trials. The best way to determine which patients may respond to an increase in arousal threshold also remains unclear at the current time. Another limitation of the present study is the relatively small sample size. However, it should be emphasised that the sample size was determined based on rigorous power calculations as described, and that the present results are quite consistent for each participant, making a spurious result unlikely.

In conclusion, trazodone increased the respiratory effortrelated arousal threshold in response to hypercapnia in obstructive sleep apnoea patients and allowed them to tolerate a higher $\mathrm{CO}_{2}$ level. The arousal threshold induced by decrementing levels of continuous positive airway pressure 
was not altered by trazodone. The effect of trazodone on arousal threshold might open new treatment opportunities in the future, for a subset of obstructive sleep apnoea patients.

\section{REFERENCES}

1 Young T, Palta M, Dempsey J, Skatrud J, Weber S, Badr S. The occurrence of sleep-disordered breathing among middle-aged adults. N Engl J Med 1993; 328: 1230-1235.

2 Younes M. Contributions of upper airway mechanics and control mechanisms to severity of obstructive apnea. Am J Respir Crit Care Med 2003; 168: 645-658.

3 Berry RB, McCasland CR, Light RW. The effect of triazolam on the arousal response to airway occlusion during sleep in normal subjects. Am Rev Respir Dis 1992; 146: $1256-1260$.

4 Veasey SC, Panckeri KA, Hoffman EA, Pack AI, Hendricks JC. The effects of serotonin antagonists in an animal model of sleep-disordered breathing. Am J Respir Crit Care Med 1996; 153: 776-786.

5 Douglas NJ, White DP, Weil JV, et al. Hypoxic ventilatory response decreases during sleep in normal men. Am Rev Respir Dis 1982; 125: 286-289.

6 Gothe B, Goldman MD, Cherniack NS, Mantey P. Effect of progressive hypoxia on breathing during sleep. Am Rev Respir Dis 1982; 126: 97-102.

7 Berthon-Jones M, Sullivan CE. Ventilation and arousal responses to hypercapnia in normal sleeping humans. $J$ Appl Physiol 1984; 57: 59-67.

8 Ayas NT, Brown R, Shea SA. Hypercapnia can induce arousal from sleep in the absence of altered respiratory mechanoreception. Am J Respir Crit Care Med 2000; 162: 1004-1008.

9 Gleeson K, Zwillich CW, White DP. The influence of increasing ventilatory effort on arousal from sleep. Am Rev Respir Dis 1990; 142: 295-300.

10 Heinzer RC, White DP, Jordan AS, Lo YL, Dover L, Schory K, Malhotra A. Trazodone increases arousal threshold in obstructive sleep apnea. Proc Am Thorac Soc 2006; 3: A316.

11 Malhotra A, Jordan AS. Did fat boy Joe need hormone replacement? Sleep 2006; 29: 16-18.

12 Stanchina ML, Malhotra A, Fogel RB, et al. Genioglossus muscle responsiveness to chemical and mechanical stimuli during non-rapid eye movement sleep. Am J Respir Crit Care Med 2002; 165: 945-949.
13 Bonora M, St John WM, Bledsoe TA. Differential elevation by protriptyline and depression by diazepam of upper airway respiratory motor activity. Am Rev Respir Dis 1985; 131: 41-45.

14 Smith PL, Haponik EF, Allen RP, Bleecker ER. The effects of protriptyline in sleep-disordered breathing. Am Rev Respir Dis 1983; 127: 8-13.

15 Hanzel DA, Proia NG, Hudgel DW. Response of obstructive sleep apnea to fluoxetine and protriptyline. Chest 1991; 100: 416-421.

16 Drummond GB. Comparison of sedation with midazolam and ketamine: effects on airway muscle activity. $\mathrm{Br} J$ Anaesth 1996; 76: 663-667.

17 Guilleminault C, Crowe C, Quera-Salva MA, Miles L, Partinen M. Periodic leg movement, sleep fragmentation and central sleep apnoea in two cases: reduction with Clonazepam. Eur Respir J 1988; 1: 762-765.

18 Veasey SC, Fenik P, Panckeri K, Pack AI, Hendricks JC. The effects of trazodone with L-tryptophan on sleepdisordered breathing in the English bulldog. Am J Respir Crit Care Med 1999; 160: 1659-1667.

19 Carley DW, Radulovacki M. M. Mirtazapine, a mixedprofile serotonin agonist/antagonist, suppresses sleep apnea in the rat. Am J Respir Crit Care Med 1999; 160: 1824-1829.

20 Castillo JL, Menendez P, Segovia L, Guilleminault C. Effectiveness of mirtazapine in the treatment of sleep apnea/hypopnea syndrome (SAHS). Sleep Med 2004; 5: 507-508.

21 Berry RB, Yamaura EM, Gill K, Reist C. Acute effects of paroxetine on genioglossus activity in obstructive sleep apnea. Sleep 1999; 22: 1087-1092.

22 Veasey SC. Serotonin agonists and antagonists in obstructive sleep apnea: therapeutic potential. Am J Respir Med 2003; 2: 21-29.

23 Carley DW, Olopade C, Ruigt GS, Radulovacki M. Efficacy of mirtazapine in obstructive sleep apnea syndrome. Sleep 2007; 30: 35-41.

24 Jordan AS, McEvoy RD, Edwards JK, et al. The influence of gender and upper airway resistance on the ventilatory response to arousal in obstructive sleep apnoea in humans. J Physiol 2004; 558: 993-1004.

25 Wellman A, Jordan AS, Malhotra A, et al. Ventilatory control and airway anatomy in obstructive sleep apnea. Am J Respir Crit Care Med 2004; 170: 1225-1232. 